\title{
Bimonthly injections of ranibizumab for age-related macular degeneration
}

\author{
Abdullah Ilhan • Ahmet Tas • Umit Yolcu • \\ Fatih C. Gundogan
}

Received: 28 October 2014 / Accepted: 20 November 2014 / Published online: 9 December 2014

(C) Springer-Verlag Berlin Heidelberg 2014

Dear Editor,

We congratulate Sawada et al. [1] for their study entitled 'Bimonthly injections of ranibizumab for age-related macular degeneration'. The authors investigated the effect of bimonthly ranibizumab injections on best-corrected visual acuity (BCVA) and central retinal subfield thickness (CRST) in age-related macular degeneration (AMD) and polypoidal choroidal vasculopathy $(\mathrm{PCV})$. The results are remarkable. At the end of the sixth month, mean BCVA had improved by $0.19 \operatorname{logMAR}$, which could be converted to 9.5 letters. This finding is really surprising, because similar results were obtained in other remarkable studies (MARINA, SATT, ANCHOR, EXTEND-1 studies). When we take a look at Figure 1 in the paper, we see that BCVA increased consistently except for a small decrease between the third and fourth month. However, Figure 2 shows that CRST decreased after the first injection, increased between the first and second months, then decreased after the second injection and so on. This shows that an

\author{
A. Ilhan \\ Ophthalmology Department, Erzurum Military Hospital, \\ Erzurum, Turkey \\ A. Tas \\ Ophthalmology Department, Agri Military Hospital, Agri, Turkey \\ U. Yolcu \\ Ophthalmology Department, Sarikamis Military Hospital, \\ Kars, Turkey \\ F. C. Gundogan \\ Ophthalmology Department, Gulhane Military Medical School, \\ Ankara, Turkey \\ A. Ilhan $(\triangle)$ \\ Goz Hastalıkları Klinigi, Erzurum Asker Hastanesi, Ataturk Bulvari, \\ 25080 Erzurum, Turkey \\ e-mail: dzilhan@hotmail.com
}

increase in CRST does not absolutely necessitate additional injections as often done in clinical practice by many retinal specialists. Figure 1 shows that BCVA increase is faster in the first month after each injection, and then the increase continues between the first and second months after the injection but with a slower rate (except between the third and fourth months). These findings show that bimonthly injections may be regarded as the border point. It is apparent that the same success may be obtained with fewer injections, and the risk of complications is decreased with such a treatment choice.

At that point we want to ask to the authors to perform correlation analyses between BCVA change and CRST change for the differences between 1st and 2nd months, 2nd and 3rd months, 3rd and 4th months, 4th and 5th months and 5th and 6th months. The change may be calculated as percentiles [for example: (second-first)/ first]. These correlation analyses would better explore the relationship between function and morphology in the first and second months after each injection.

Conflict of interest statement All authors certify that they have NO affiliations with or involvement in any organization or entity with any financial interest (such as honoraria; educational grants; participation in speakers' bureaus; membership, employment, consultancies, stock ownership, or other equity interest; and expert testimony or patent-licensing arrangements), or non-financial interest (such as personal or professional relationships, affiliations, knowledge or beliefs) in the subject matter or materials discussed in this manuscript.

\section{References}

Sawada T, Kakinoki M, Wang X, Kawamura H, Saishin Y, Ohji M (2014) Bimonthly injections of ranibizumab for age-related macular degeneration. Graefes Arch Clin Exp Ophthalmol 252:1545-1551. doi:10.1007/s00417-014-2612-8 